\title{
El loro de Lizardi. Lectura en voz alta del Periquillo Sarniento ${ }^{1}$
}

\author{
ENRIQUE FLORES \\ Instituto de Investigaciones Filológicas, UNAM
}

Habló el perico y me dijo: “[...] He oído leer tus papeles [...]".

Lizardi

Pericos y periquillos

Entre las estampas que burilo un tal Mendoza para la primera edición de la Vida de Periquillo Sarniento (1816), hay una que le sirve de portada y que acompañó la entrega de los primeros pliegos a los suscriptores. ${ }^{2} \mathrm{La}$ imagen condensa los cinco tomos de la novela, como un pequeño teatro de la memoria que acumula

${ }^{1}$ Este trabajo forma parte del proyecto sobre "Cultura oral y cultura escrita. 1700-1820" que estamos realizando la Dra. Margit Frenk y yo en el Centro de Estudios Literarios del Instituto de Investigaciones Filológicas de la UNAM. Por lo demás, ni la investigación propiamente dicha ni la redacción final de mi trabajo serían las mismas sin las observaciones de la Dra. Frenk y sin su minuciosa lectura del texto.

${ }^{2}$ Las primeras entregas del Periquillo aparecieron en la ciudad de México en febrero de 1816 (Spell 145). Según Jefferson Rea Spell, el Mendoza que firma los treinta y siete grabados de la primera edición podría ser "Don Mariano Mendoza, arquitecto y académico de la Real de San Carlos", consignado en la lista de los "Señores subscriptores" que se incluye al final del tomo primero de la novela (8: 213). (En adelante, para referirme al' Periquillo, cito como 8 y 9 los volúmenes de las Obras de Lizardi correspondientes a la novela en la edición de la Nueva Biblioteca Mexicana.) 
restos y fragmentos de imágenes en torno a la figura del protagonista: figura silente de Pedro Sarmiento, emparentada con lá estampita hagiografica, cruzada de símbolos de su vida. Y al pie de la estampa, impresa en correcta letra manuscrita, se lee una octava anónima que podemos suponer compuesta por el propio Lizardi y que invita a escuchar la vida de Periquillo:

No es éste el Periquillo que cantando

o haciendo no sé qué se llevó el viento.

Este Perico, sin cantar, va dando

a muchos mil lecciones de escarmiento.

Su fin es deleitar aprovechando

a quien su vida quiera leer atento.

Tal el carácter es de mi Perico.

Escucha pues, lector, que yá abre el pico.

Ambas, la imagen visual y la octava manuscrita, dan testimonio de una realidad muy difundida en el setecientos: la existencia de una categoria de lectores extraños a la palabra escrita, no sólo por razones de analfabetismo, y que podemos llamar "lectores iletrados". 3 Aunque se presenta a manera de fábula, la estrofa cumple con la función del exordio de los sermones y cantares de ciego: expresa el fruto de la lección y convoca la atención del auditorio. Ella misma atestigua el hábito de la lectura en voz alta, la vocalización de manuscritos e impresos en el virreinato.

A la mudez de la estampa corresponde, figuradamente, la voz chillona de Perico, narrador locuaz, hablador, charlatán incorregible. Una sátira anónima del XVIII, recogida por la Inquisición novohispana, incluye entre una gran variedad de tonos populares

${ }^{3}$ La categoría de los "lectores iletrados" surge una y otra vez en los análisis de la literatura popular clandestina y semiclandestina del siglo XVII. Así, a propósito de los lectores de pronósticos (género frecuentado por $\mathrm{Li}$ zardi): "De acuerdo con Isidoro Ortiz Gallardo [sobrino de Torres Villarroel], se leían en alta voz, como las gacetas y los mercurios e historias y romances de ajusticiados. Pero también es posible que no fuera necesario ser alfabeto para leerlos, puesto que las ilustraciones y figuras astronómicas y astrológicas de que tan profusamente venían adornados apelaban al signo más que al texto escrito" (Zavala 208). 
y semipopulares un "tono de periquillo". ${ }^{4}$ Otra sátira manuscrita de principios del XIX, que reproduce el diálogo de un consultor y un médico, se titula El perico y la rabia. ${ }^{5}$ Perico y Marica charlan incansablemente en los papeles semiclandestinos del siglo XVIII español. ${ }^{6}$ La misma palabra perico - "[papagayo] que mejor aprende a hablar y de más fácil domesticación en los hogares", según Santamaría - ha dado lugar, en México, a la expresión festiva y familiar echar perico, o lo que es lo mismo, "hablar locuazmente, hablar sin seso, charlatanear" (Santamaría s.v. "Perico").

"Tal el carácter es de mi Perico", dice el coplista, aludiendo al carácter ejemplar del relato ("mi Perico") y al del relator enmudecido en la estampa. Su copla solicita la atención del público, del "lector", del oyente, en virtud de una escala de significados que aviva la escucha - literal o figurada- de las "lecciones" de Periquillo. Leer es oír, escuchar la parla de la lectura. Escribir es hablar, otra manera de echar perico: "Escucha pues, lector, que ya abre el pico". Una figura de la oralidad - el perico- permea la recepción, entonación y estilo del Periquillo Sarniento. ${ }^{7}$

${ }^{4}$ La Relación verídica [...] de la procesión del Corpus de la ciudad de la Puebla (1794) incluye en su repertorio de improvisaciones carnavalescas algunas parodias sacras - un "tono de villancico", y coplas paródicas de "invitatorios" y "responsorios"-, pero también una "décima vulgar", el verso de "cierta cucaracha", un "tono de gallo ronco" y un "tono de periquillo" (Miranda / González Casanova 197-218). "Tono" significa aquí zonada, composición vocal, musical, popular.

5 Transcribo un fragmento del diálogo: "Consultor: Aquí entra mi consulta: ¿yo debo reírme de la opinión de mi perico, como se rio el otro, o debo seguirla? Médico: Señor mío, yo me río de su consulta de usted, porque ¿quién hace caso de lo que dice un perico? Consultor: Hay pericos y pericos, y el mío no es como los que usted habrá visto, porque sabe leer, escribir y contar. Médico: ¿Y todo eso lo hace con el pico?" (Guía de Forasteros I. 14 (1984): 1, 10).

${ }^{6}$ Los ciegos Perico y Marica son "personajes tradicionales de la literatura de cordel" (Zavala 19). Y lo que define a estos "parlanchines" y "eternos dialogantes" es, como reza el título de un pliego expósito del XVIII, "su acostumbrada parola", su labia y su conversación (Zavala 268, 317, 324).

${ }^{7}$ Una lúcida indagación sobre el uso de la palabra leer y las costumbres de lectura en voz alta en el Siglo de Oro se encontrará en los artículos de Margit Frenk. Cf. la bibliografia de este trabajo. 


\section{El testamento}

Perico no se cansa de repetir que escribe y habla para sus hijos. Comienza el prólogo de su vida diciendo: "Cuando escribo mi vida, es sólo con la sana intención de que mis hijos se instruyan alguna cosita en las materias sobre que les hablo" (8: 34). La frase le sirve como argumento contra sus detractores: "Mucho menos que no escribo para todos, sino sólo para mis hijos, que son los que más me interesan y a quienes tengo obligación de enseñar" (8: 35). Y concluye al final del prólogo: "En fin, tengo un consuelo, y es que mis escritos precisamente agradarán a mis hijos, para quienes en primer lugar los trabaje" (8: 36$)$.

Lizardi ha construido la novela como un testamento de Periquillo, de acuerdo con la forma tradicional de un género - el testamento de un moribundo- calcado de una práctica jurídica que mezcla formas de oralidad y escritura. ${ }^{8}$ De ahí la oscilación que se percibe en el prólogo: Perico escribe su testamento y habla en él a sus hijos; no dicta, pero sí improvisa, y espera una lectura en voz alta del libro.

Huellas de esa voz testamentaria subsisten en el curso de las entregas. Algunas veces se trata de apoyos verbales: "Es menester que sepáis, hijos míos (por si no os lo he dicho)..." (8: 50). Otras veces se prevé la reacción de los oyentes: "Paréceme que al leer estos renglones exclamáis..." (8: 92). Otras veces, en fin, Perico exhibe las muletillas de sus innumerables sermones domésticos poniéndolas en labios de una "buena vieja", como un discurso oral: "Ya ves, hija...", "Conque hija...", "Conque anda, hija...", "Así es, hija mía...", "Por último, hija mía..." (8: 200202).

${ }^{8}$ Sobre la "realización vocal" del testamento, su carácter "fundamentalmente oral" (a pesar de consignarse por escrito) y el género de los testamentos poéticos, cf. Zumthor 103-104. La idea de un "testamento del perico" recuerda, por lo demás, un género cómico de rancio abolengo: los testamentos de animales. Testamentos del asno, del gallo, del cerdo, del gato, del ratón, de la pulga, el caracol y el caballo pueden hallarse en el repertorio de la literatura de cordel desde hace siglos (cf. el artículo y la recolección de Amades). 
Se dirá que el verdadero testamento de Perico aparece al término de la novela, en las "Notas de El Pensador", como un ritual de carácter técnico y escriturario completamente ajeno a la vida doméstica del testador (9: 396-397):

Hizo llamar al escribano y otorgó su testamento con las formalidades de estilo. En él declaró tener cincuenta mil pesos en reales efectivos puestos a réditos seguros en poder del conde de San Telmo, según constaba del documento que manifestó certificado por escribano y debía obrar cosido en el testamento original, y seguía:

"Item declaro que es mi voluntad [...]"

Las tres "disposiciones testamentarias" (relativas a finanzas y a negocios de caridad pública) se olvidan de los hijos de "don Pedro Sarmiento". A ellos les reserva Perico, concluida la escritura del testamento, un último discurso agonizante, malamente apoyado sobre muletillas. Cito sólo una de ellas: "A vosotros, hijos de mi corazón, Łqué puedo deciros?" "Os dejo escrita mi vida" (9: 399).

A este segundo testamento oral, que tiene a Lizardi como testigo, ${ }^{9}$ corresponde la Vida de Periquillo Sarniento. Perico la escribe de su propia mano, sin dictados, notarios, testigos ni escribientes. Pero la formula testamentaria se impone desde el comienzo de la novela, cuyas primeras líneas consignan la postración del narrador moribundo, sus deseos y sus súplicas, la voluntad de heredar su vida como lectura.

Al final de todo, más allá de las últimas voluntades, aparece -en la ficción de lectura propuesta por Lizardi- el espectro de la palabra oral, el fantasma de una lectura doméstica: "Hijos míos: después de mi muerte leeréis por primera vez estos escritos" $(8: 45){ }^{10}$

9 "Sentado yo a la cabecera, y rodeada su familia de la cama, les dijo con la mayor tranquilidad..." (9:398).

${ }^{10}$ Terminada ya la redacción de este artículo, he podido consultar el estudio de Edmond Cros que tiene como eje la "estructura testamentaria" del Periquillo. Para Cros, "le texte dans son entier doit être considéré comme le testament spirituel d'un père de famille" (157). Pero esa estructura no es 
Hablas y estilos

Que Lizardi espera una lectura en voz alta del testamento lo probaría el epígrafe del segundo capítulo del libro, cuyas particularidades - dice Lizardi- "sabrá el que las leyere, las oyere leer o las preguntare" (8: 54). Pero incluso esta expresión categórica pierde valor si la entendemos como una parodia de otro epígrafe del Quijote (2: cap. 66): "Que trata de lo que verá el que lo leyere, o lo oirá el que lo escuchare leer".

La polémica de Lizardi con "Uno de Tantos"11 _ lector y censor de la novela - aporta otros indicios de lectura oral. Esta vez, las huellas de oralidad aparecen en el estilo de la novela. Objeta el censor que un sepulcro, un hospital, un calabozo "no pueden presentarse bajo un aspecto ridículo". A Lizardi la objeción le parece "trivial": "si no se pueden poner ¿cómo yo los he puesto?" Y agrega: "¿Habrá quien no se ría al oír las aventuras de Periquillo en su prisión, en el hospital y cuando el robo del cadáver?" (8: 23-24).

La escucha y la risa de los oyentes, el valor otorgado a la escena de lectura, el argumento pragmático de Lizardi (que atestigua "el aprecio con que en el día se ve [su obra], la ansia con que se busca, el excesivo precio a que la compran y la escasez que hay de ella", 8: 25), sugieren que el autor fue el primer testigo de la lectura en voz alta de su novela.

Para "Uno de Tantos", Lizardi es el primer escritor que novela en el "estilo de la canalla". No es sólo que en ella encontremos a "las peores gentes de la sociedad obrando ordinariamente según las vemos, hablando según las oímos". Ni se trata tampoco,

simple: "le Periquillo Sarniento [est] sémantisé par deux testaments imbriqués l'un dans l'autre, et présenté à son tour explicitement comme texte testamentaire" (158).

11 La crítica de "Uno de Tantos" (o de Manuel Terán, autor oculto tras ese seudónimo) apareció en el Noticioso General en febrero de 1819. El mismo periódico publicó la respuesta o Apología de Lizardi, reproducida en la cuarta edición de la novela y en la edición de la Nueva Biblioteca Mexicana. (No he podido consultar el texto de Manuel Terán, así que me refiero a las citas incluidas en la Apología, en las notas a ésta y en el comentario de Alfonso Reyes a la discusión.) 
únicamente, de la clase de gentes elegidas por Lizardi para "hablarles al alma", de acuerdo con la crítica de otro censor anonimo del Periquillo: 12

Tiene manojos o racimos de sentencias, autoridades y refranes para toda clase de personas; pero principalmente a las del pueblo bajo les habla al alma y las va a buscar por todos los andurriales, cárceles, presidios, hospitales, tabernas, bodegones (Reyes 172-173).

Para "Uno de Tantos", el giro bajo y la frase tabernaria son patrimonio del autor, cuyo estilo pasa de la sencillez a la bajeza "y con harta frecuencia a la grosería del de la taberna". Lo cual no obsta para que nos ensarte "una cuaresma de sermones", muy al estilo, por cierto, de los predicadores populares, que gustaban de predicar frente a las cantinas ante un público iletrado y plebeyo. ${ }^{13} \mathrm{Su}$ "locución", en fin, le parece al censor "tan uniforme como en su acción el chorrillo de alcantarilla" (8:21).

Ciertos rasgos de estilo del discurso oral "esclavizan" al Perico de Lizardi. "El autor del Periquillo se esclavizó él mismo": "la

${ }^{12}$ Me refiero a "El Tocayo de Clarita", que firma un artículo del Noticioso General impreso en diciembre de 1818: "Trátase de un breve cuento crítico cuyo asunto, por infantil, merece callarse. De paso se cita al Periquillo" (Reyes 172). Por supuesto que la expresión del crítico - "les habla al alma"- es un giro todavía habitual, lo mismo que el uso de hablar por escribir mencionado antes. Pero cuando Lizardi escribe que les habla a sus hijos y cuando el crítico apunta, refiriéndose a las gentes del pueblo bajo, que Lizardi les habla al alma, sus palabras no son ajenas a una situación discursiva oral muy desvanecida para nosotros.

13 El padre Miguel Castillo, "apóstol de los barrios de México", practicó algunos métodos nuevos de la elocuencia sagrada, tales como el diálogo desde el púlpito y la pérdida voluntaria de hojitas (con frases relativas al pecado y las penas infernales) por las calles: "algunos las tomaban por avisos del cielo". "Una vez dispuso su púlpito improvisado cerca de una cantina que solía ser muy frecuentada. De pronto sacó unas estampas grandes, de papel, y las dio a unos niños, pero con la condición de que estuvieran buen rato mostrándolas, en las cercanías de la taberna, sin decir una palabra. Eso bastó para que por entonces no entraran a beber". "Cuando se hablaba de su mucha clientela, a todas horas, en el confesionario, lo tomaba [...] jocosamente: «Son peladitos los que me buscan; apenas encontrarán ustedes señoras o señores que dejen coche a la puertan" (Maneiro 530-541). 
manía de explicar dilata enfadosamente los períodos"; acumula digresiones sobre digresiones; carece de "variedad de locución". Su estilo parece "propio en un padre que instruye a sus muchachos" (Reyes 173), nunca en un novelista.

Para "Uno de Tantos", Lizardi es peor que Escarrón, "el cínico de la literatura". Confunde la "utilidad común" y los "medios" privados de que se vale un padre cuando educa a sus hijos. Ofende al "público" de la Nueva España al comparar la lectura del libro (inequívocamente oral, como otras lecturas tradicionales) con las patrañas de una "vieja cuentera":

¿Esto sí que es insultar a las gentes! El público de Nueva España es en el concepto de este autor una congregación de parvulillos, y él una vieja cuentera dispensada de toda regla y arte por la imbecilidad de sus oyentes (Reyes 175).

\section{Públicos}

En la exclamación de "Uno de Tantos", convergen dos imágenes del "público de Nueva España". De un lado, la "congregación de parvulillos", los niños que escuchan las lecciones de su maestrescuela. De otro lado, el público de la "cuentera", los "oyentes" imbéciles que se reúnen para oír sus patrañas y disparates. Esta última imagen proviene del "Prólogo en traje de cuento" al segundo tomo de la novela, que comienza con una formula de relato oral: "Ha de estar usted para bien saber, señor lector, y saber para contar" (8: 221).

Se trata, está claro, de una parodia, de un "traje" con que se viste el prólogo, de un disfraz, como lo muestra esa curiosa costura de una formula de tipo oral con otra formula escrituraria: "señor lector". Pero ese traje es un "traje de cuento", y por lo tanto (en el sentir del censor de Lizardi) una invención que insulta al "público de Nueva España".

Pero ¿quién es el "público" de Nueva España? Dada la ambigüedad de la palabra "público" en el siglo XVIII, parece difícil, si no imposible, determinar inequívocamente su significado: “"el 
común del pueblo o ciudad"?; ¿'lo escogido de las gentes sensatas"?; “"la plebe"? 14 Este último sentido se aleja, evidentemente, de la noción de "público" que tenía "Uno de Tantos", pero no del "público" al que hablaba Torres Villarroel, uno de los autores favoritos de Lizardi. ${ }^{15}$ Más próximo a nosotros, en 1832, y con cierta amargura, Larra titulaba su primer artículo periodístico: “¿Quién es el público y dónde se encuentra?” (Hafter 46-47).

En los prólogos de su novela, Lizardi no se dirige al "público", sino a "los lectores" (8: 28), a los "serenísimos lectores" (8: 33), al "señor lector" de su "Prólogo en traje de cuento" (4:221). Si pregunta "qué juicio forma de [la novela] el público", es sólo para advertir "que el público es todos y ninguno; que se compone de sabios e ignorantes; que cada uno abunda en su opinión; que es moralmente imposible contentar al público, esto es, a todos en general" (8: 221). Apelar al "tribunal del público" significa atender a la diversidad de gustos, lecturas y lectores, pero también a los no-lectores, ya que el "público" de la novela incluye a los que no la leen ("otros no la leen para nada"), a los que "la leen y no la entienden", y a los que la usan como "papel sucio" — cacata carta (8: 222). ${ }^{16}$

¿Quienes son, pues, los lectores de la novela?: ¿"el niño travieso"?, ¿"el joven disipado"?, ¿"la señorita modista”?, ¿"el pícaro y tuno descarado"? (9: 414). Muchas sátiras del XVIII

14 Cito tres de las definiciones incluidas por Hafter en su importante artículo: la del Diccionario de Autoridades, la de Mariano José de Larra y la de Diego de Torres Villarroel (46, 47 y 55).

15 "Para Diego de Torres Villarroel [...], el público era inequívocamente plebeyo. $Y$ de entre todos los escritores de aquellas fechas acaso sea el único que estuviera en buenos términos con ese público [...]. Lejos de condescender a $\tan$ humilde auditorio, Torres lo cultiva como escritor, y a menudo confiesa sin empacho que va en busca de su dinero" (Hafter 55-56).

16 "Otros, finalmente, la comparan a los Anales de Volusio", dice el texto. Lizardi alude, eufemísticamente, a un verso de Catulo: Annales Volusi, - cacata carta (carmen XXXVI, 1). La misma alusión a Volusio aparece en el tercer Cajoncito de Lizardi: "¿Qué juicio hace usted de la Alacena de Frioleras? ¿No es verdad que es un periódico despilfarrado y digno de estar junto a los Anales de Volusio, de los que dijo Catulo: Anales de Volusio, ipapel puerco!?" (Obras 4: 186). 
convierten al público en materia de burlas y prestidigitaciones. ${ }^{17}$ Lizardi adivina entre sus lectores a "plebeyos, indios, mulatos, negros", pero ¿son sus lectores o sus personajes? (8: 33). La comunicacion entre autores y lectores apenas ha comenzado a romperse. En cierto modo, el "público" asiste a la novela como se asiste a una funcion de teatro. Por eso Lizardi puede decir, citando la "fábula del oso bailarín", de Tomás de Iriarte: "Tampoco soy de los que aspiran a tener un sinnúmero de lectores, ni apetezco los víctores de la plebe ignorante y novelera" (8: 222).

\section{Lectores y compradores}

Los prólogos de Lizardi evitan aludir al origen social de sus lectores. Señalan, si acaso, su condición (o corrupción) moral, y si parodian las dedicatorias al uso -plagadas de "títulos" y blasones familiares-, es con el fin de burlarse de los hábitos protocolarios, estamentarios, escriturarios, del Antiguo Régimen cultural novohispano (8: 32-33).

El autor ofrece su novela como tributo "a los reales... méritos" de sus lectores. Ni los vicios, ni los defectos, ni la calidad social de esos "mecenas" le importan un comino a Lizardi, con tal, como dice, de que "costeéis la impresión con algunos polvos de añadidura" ( $8: 33){ }^{18}$

Los verdaderos lectores de Lizardi son sus compradores: "los que leen las obras a costa de su dinero"; "los que costean la

17 El público de la sátira se incorpora como protagonista. Así, la Relación verídica contiene una extensa dedicatoria "a la señora doña Plazuela del Volador", refugio de pícaros y "baratilleros" que son personajes de la relación $y$, a la vez, lectores del manuscrito: "Y aunque conozco que esta obra no tendrá lugar en celdas de religiosos capuchinos, en estudios de abogados ni en librerías de conventos [...], sírveme de consuelo que no obstante será bien admitida en los cuarteles de Palacio, entre los archicofrades del baratillo, en los coristados y colegios y en las casas donde hubiere estudiantes" (Miranda / González Casanova 215).

${ }^{18}$ Lizardi había dedicado su primer periódico - El Pensador Mexicanoal "señor lector": "A usted dedico mi tal cual trabajo, porque ¿a quién sino al lector se le dedican los libros? Si le gustare podrá comprar este papel y los que le sigan; si no, tan amigos como siempre" (Obras 3: 34). 
impresión" (8: 32). Lectores-compradores, aunque a veces parezcan ser más "compradores" que "lectores":

Es verdad que apetecería tener no ya muchos lectores, sino muchos compradores, a lo menos tantos cuantos se necesitan para costear la impresión y compensarme el tiempo que gasto en escribir (8: 223). Lo que me interesa es que compren la obra, y después más que la tiren o la quemen (8: 39$)$.

Se trata, pues, en primer lugar, de una cuestión de costos, como advierte Lizardi en el Prospecto de la novela: "atendidos los exorbitantes costos y pensiones que tienen los autores que sufrir en este Reino, y el poco consumo que debe esperar en obras de esta naturaleza [...]" (8: 8). La misma idea vuelve a aparecer en el prólogo del libro:

-Sí, amigo, le dije; y ésta es una de las trabas más formidables que han tenido y tendrán los talentos americanos para no lucir como debieran en el teatro literario. Los grandes costos que tienen que lastarse en la impresión de unas obras abultadas en el Reino [...] (8: 29).

Y esos costos incluyen el precio de impresión, el flete y la encuadernación, el papel (cuya carestía había obligado a Lizardi a suspender El Pensador Mexicano), ${ }^{19}$ el salario de los escribientes y los libros comprados como herramientas:

-Ya parece que veo que gastas el dinero que no tienes en hacer poner en limpio y con mucha curiosidad tus cuadernos (8: 30). -Esta obrita me ha costado algún trabajo; y tanto más cuanto que soy un chambón y la he trabajado sin herramienta" $(8: 31) .{ }^{20}$

${ }^{19}$ Un número extraordinario de El Pensador advertía a fines de 1812 que "el papel está subiendo terriblemente, hoy vale a un peso la mano; y los costos de imprenta, repartidores y expendedores hacen temer que dentro de pocas semanas no se pueda dar el ejemplar a real sin perder" (Obras 3: 125). Al poco tiempo, Lizardi publicaba su Despedida: "Suspendo por ahora mi efímero periódico, porque el papel me ha costado y está costando muy caro, de modo que no me ofrece cuenta proseguir; si abaratare se continuará" (Obras 3: 111).

${ }^{20}$ El tema de la carestía de los libros surge una y otra vez en el siglo 
Paródica o no, la imagen de los lectores-compradores revela una nivelación, un rebajamiento de la lectura y los lectores. Si los lectores son meros compradores, la ausencia de lectura forma parte del universo de la lectura (y ello no ya en funcion de una "lectura iletrada", sino como una falta absoluta de lectura). Ciertas burlas tradicionales parodian este aspecto mercantil de la lectura, como es el caso de un tópico satírico muy repetido en el siglo XVIII, relacionado con el valor "pirotécnico" de los pliegos sueltos y el uso de los papeles impresos como mera envoltura de mercancías. ${ }^{21}$ Lizardi apela a ese tópico en el Prospecto de su novela:

¿Qué juicio podrá hacer de mi trabajo el que oiga gritar a los muchachos: Vida de Periquillo Sarniento? [...]. Se pasarán de

XVIII novohispano. Eguiara lo introduce en sus Prólogos a la Biblioteca Mexicana (121 y 169-171). Para Cayetano Cabrera y Quintero, autor del Escudo de armas de México (1746), la mayor desgracia de las obras escritas en las Indias es "que se hayan sabido hacer, no publicar: se hayan sabido escribir, no imprimir; quedándose, o totalmente en tinieblas, sobornando una posessión avarienta, o aun entre sombras, en desfiguradas copias, y traslados" (Cabrera xxxi). Entre las causas de esa oscuridad, de la pervivencia de una cultura del manuscrito, apunta el autor "la violenta escasez del papel" para imprimir - y aun para escribir - las obras; la "gratificación de amanuenses" (erogada de "nuestro no muy largo bolsillo"); y por último, el "otro escollo de las prensas, tormento de la pluma en estos países, Caribdis de las mercaderías y vasos más capaces, que se dejan morir y sepultar por no passarlo" (Cabrera xxxii-xxxiii).

${ }^{21}$ La Relación satírica mencionada en la nota 3 termina con la siguiente quintilla: "Y si aquesta obra, rufián, / nunca te gustare leer, / licencia te doy, pián, pián, / de que la puedas coger / para envolver azafrán" (Miranda / González Casanova 215). En la primera entrega de su Diario Literario de México (marzo de 1768), José Antonio Alzate se dirigía a sus lectores diciendo que no estimaba en tan poco las obras de su pluma "que me guste verlas destinadas al brazo secular de los semilleros o coheteros" (Alzate 7). La alusión a los coheteros se reitera en el "Prólogo" de una obra impresa en 1781 y firmada por un supuesto Felipe de Bendiaga, que habría dejado como única herencia "varios papeles sucios y manchados", "escritos de muy mala letra": "El heredero, que sólo apartó los papeles que pudieran servirle [por estar en blanco], no quiso perder ni aun éstos [los "sucios y manchados"], y quiso ver si los comprarían en los tendajones donde se vende azafrán: Et piper, et quidquid chartis amicitur ineptis [" $\mathrm{y}$ pimienta y todo aquello que se envuelve con papeles inservibles"]; o en las coheterías, donde pudieran servir para hacer triquitraques" (Trabulse 15-16). 
largo y no habrá quien me compre un capítulo ni por cuartilla, quedándome yo con el original y lo impreso para dar con ello en la tienda de un boticario o de un pulpero (8: 5).

Mezcladas en este curioso párrafo, corren formas orales de difusión (el pregón de la novela), formas manuscritas (el "original") y formas impresas (los pliegos sueltos). La viva imagen que ofrece el pregón contrasta con el cúmulo de papel olvidado de la novela. El Periquillo como novela efímera: la letra escrita o impresa carece, en este párrafo, del valor de fijeza que frecuentemente se le atribuye: es tan efímera, tan susceptible de ser borrada como la mera difusión oral.

A veces, el tópico de la envoltura parodia los fracasos del escritor pobre: "Hasta que cansado de andar por todo el alphabeto [...], te aburres y desesperas, y das con tu pobre trabajo en una tienda de aceite y vinagre" (8: 31$)$. A veces resuelve sus desventuras, como cuando anima a sus lectores a comprar "cinco o seis ejemplares cada uno", y a suscribirse, a lo menos, "por cinco o seis ejemplares", "aunque después os deis a Barrabás", "aunque me critiquéis de arriba abajo", y "hagáis cartuchos o servilletas de los libros" (8: 33). ${ }^{22}$

Como apunté antes, tras ese tópico satírico se oculta una costumbre muy arraigada de lectura: la lectura efímera, fugaz, circulante de los pliegos sueltos. Las "Advertencias generales a los lectores" recomiendan tratar de conservar la obra, "sin prestar los capítulos indistintamente a cualquier persona, ni menos fiar las estampas a la discreción de los muchachos" (8: 38). En cuanto a los "señores subscriptores", han de impedir que reciban los pliegos el "criado o criada", "quien tal vez lo ensucia, o lo rompe, o

22 Otras alusiones a coheteros, boticarios y tenderos pueden hallarse en los periódicos de Lizardi. El Pensador Mexicano: "las más veces es el cohetero, el pulpero o el boticario el heredero de [mi] trabajo?" (Obras 3: 44); "ni los coheteros me los querrán pagar por papel sucio" (Obras 3: 80); "yo me compondré con el tendero o el boticario" (Obras 3: 156). Alacena de Frioleras: "despachar los ejemplares sobrantes por la posta a los hermanos boticarios y tenderos, para que los destinen a alcartaces" (Obras 4: 24); "¿pues qué los boticarios y tenderos les harán el desaire?" (Obras 4: 220). 
lo presta, o lo vende, o de cualquier otro modo lo extravía" (8: 39). De ahí otra advertencia de Perico a sus hijos: "leed para vosotros solos mis cuademos, o en caso de prestarlos [...]" (8: 45).

Lizardi no lo dice, pero es probable que la costumbre de prestar los "cuademos" fuera acompañada de su lectura en voz alta, tan perjudicial para el bolsillo del autor como la pérdida de capítulos para la cabal permanencia de la obra. ${ }^{23}$

\section{Modalidades de lectura}

Volvamos, pues, al "perico" de Lizardi, a su charlataneo, al hablar locuaz y sin seso de Periquillo. La copla inicial nos llamaba a escuchar la parla de Perico, real o figuradamente, pero para nosotros es preciso leer la novela de Lizardi, sin que lo efímero ni lo vocal intervengan en la lectura. ¿Qué significa leer la parla de Perico? ¿Qué significa la palabra "leer" en el Periquillo? ¿Qué significa la expresión "saber leer" en una novela de educación, dirigida -ficticiamente - a unos "párvulos", a los hijos del relator y protagonista? O en otros términos: ¿cómo aprende a leer nuestro Periquillo?

Volvamos al segundo capítulo de la novela, aquel cuyo encabezado parodiaba uno del Quijote: "En el que Periquillo da razón

${ }^{23}$ La literatura satírica del XVIII mezcla formas orales, manuscritas e impresas de difusión sin discontinuidad aparente. Pero es siempre una literatura circulante, callejera, de la plaza pública. En 1778, la Inquisición quiso descubrir al autor de una sátira anónima: "La encuesta para descubrir al autor fue larga y de ningún resultado: por el tribunal pasaron confesores, «españolas doncellas», presbíteros, «monigotes de sagrario», mozas del Coliseo, viejas poblanas, boticarios, amanuenses, escribanos, viudas, moriscas, sastres, hasta que se lleg6 a un liador de cigarrillos quien dijo haber encontrado la sátira en un basurero, con lo que se suspendió el proceso" (González Casanova 131). En cuanto al verídico autor de la Relación satírica de 1794, va autorizado por una paródica "Licencia de ordinario" que atestigua -con otros muchos elementos y a pesar, o a causa, de su carácter satírico- el horizonte de oralidad que organiza la recepción del pliego: "Y para que conste, por no saber escribir ni yo ni mi escribiente, lo firm6 mi cochero Pedro habiendo consultado con mi tía doña Juana. Loco sigilli" (Miranda / González Casanova 200). 
de su ingreso a la escuela, los progresos que hizo en ella, y otras particularidades que sabrá el que las leyere, las oyere leer o las preguntare" (8: 55). No parece casual que un capítulo relativo a las lecciones de lectura y escritura comience con un juego de palabras asociado al uso, ambiguo, de la palabra "leer", que puede referirse, o bien a una lectura silenciosa, privada, o bien a una lectura en voz alta, pública, que admite - como en otra escuela de primeras letras - la intervención de los "párvulos" u oyentes.

Allí expone Perico lo que él entiende por "saber leer", a través de una doctrina de las modalidades de lectura:

No todos los que leen, saben leer. Hay muchos modos dc leer, según son los estilos de las escrituras. No se han de leer las oraciones de Cicerón como los Anales de Tácito, ni el panegírico de Plinio como las comedias de Moreto. Quiero decir que el que lee debe saber distinguir los estilos en que se escribe, para animar con su tono la lectura, y entonces manifestará que entiende lo que lee y que sabe leer (8: 57).

"No todos los que leen, saben leer": frase ya de por sí significativa, que aisladamente podría ser empleada lo mismo a proposito de una lectura silenciosa que de una lectura en voz alta, con significados divergentes. Podría referirse a un lector analfabeto, que no sabe leer en el sentido que hoy le damos a esa expresión - saber leer-; a un lector que no sabe interpretar la lectura, que la malentiende, que no sabe entender el sentido de la lectura; o finalmente, como parece indicar el contexto de la frase, a un mal lector intérprete (en el sentido musical del término) de una lectura en voz alta, de una performance vocal de la lectura. Lo importante, en todo caso, es señalar la ambigüedad semántica que mezcla al lector, al intérprete y a los oyentes de la lectura.

Hay un "leer" y un "saber leer". "Saber leer" implica "distinguir los estilos en que se escribe", implica entender lo que se está leyendo y conocer (o reconocer) "los estilos de las escrituras". Pero eso no es todo. Hay un vínculo que une al estilo con la entonación de la lectura en voz alta. "Saber leer" supone "saber distinguir los estilos en que se escribe, para animar con su tono la lectura". La lectura es un arte: un acto de comprensión que no 
llega a animarse sino con una técnica de entonación, de lectura en voz alta. ${ }^{24}$

Perico describe los "modos más comunes de leer":

Muchos creen que leer bien consiste en leer aprisa, y con tal método hablan mil disparates. Otros piensan (y son los más) que en leyendo conforme la ortografía con que se escribe quedan perfectamente. Otros leen así, pero escuchándose y con tal pausa que molestan a los que atienden. Otros, por fin, leen todo género de escritos con mucha afectación, pero con cierta monotonía o igualdad de tono que fastidia (8: 57 ).

"Leer aprisa" es un mal leer, pues los que leen así "hablan mil disparates", ya sea que entiendan o no lo que leen. Leer "conforme la ortografía" es un mal leer, en la medida en que se atiene a

${ }^{24}$ Este vínculo de entonación y lectura no es, por supuesto, un aspecto original del Periquillo. Todo el sistema de las lecciones de lectura descansa, en el siglo XVII, sobre ese vínculo, ya sea que se aplique el método del deletreo o el más modemo del silabeo: "Los maestros particulares usaban el método individual, en el cual cada alumno se acercaba al escritorio para pronunciar letras o sílabas de la cartilla o silabario. Algunos utilizaban carteles grandes que tenían el alfabeto y sílabas escritas con letras de gran tamaño. Colgaban los carteles en la pared y con un puntero de otate el maestro señalaba una sílaba para que todo el grupo la pronunciara, logrando de esta manera la coordinación oído-ojo [...]. Los alumnos, al ver lo indicado por el maestro, recitaban en voz alta en coro" (Tanck 65).

Entre los defectos del método del deletreo, estaba el "tonillo" o "cantinela" típicos de los alumnos de primeras letras, que los reformadores trataron de "desterrar" (Tanck 66). A este método se opuso, en México, el de Montero, que quiso enseñar a "leer con puntuación", en una época en que la puntuación indicaba los tonos y pausas de la lectura, y cuyos "grados ortológicos" apuntaban a la entonación de la lectura en voz alta: "hacer pausa más larga y dar tono a los periodos de colones imperfectos y perfectos o punto y coma y dos puntos"; "pronunciar con la voz algo ligera y admirarse haciendo pausa"; "estar instruido para deletrear y decorar todos los tonos, ya aflorando la voz común en el paréntesis, ya tratando con imperio, ya explicando los afectos del alma de dolor, de tristeza, de alegría, de terror, de espanto, etc." (Tanck 66, n. 41). Lectura, entonación, puntuación: todo apuntala una noción del texto como partitura.

Cf., sobre este punto, el artículo antes citado de Margit Frenk (1986), un cuidadoso análisis de los antiguos tratados de ortografía como testimonios de lectura en voz alta. 
un criterio puramente formal y gráfico de corrección, desoyendo el sentido que las palabras cobran por la puntuación y la entonación de la lectura. Leer "escuchándose" (en voz alta y para sí mismo) es un mal leer, puesto que las pausas de esta lectura son molestas "a los que atienden", es decir, al auditorio de la lectura. Una lectura "monótona", por fin, es una mala lectura, puesto que se revela incapaz de poner en juego la variedad de tonos que atrae la atención de los oyentes, o dicho de otro modo, la politonalidad que exige una performance oral de la lectura.

Todas estas modalidades de lectura conciernen al juego de la palabra "leer" en el ámbito de la lectura en voz alta. Es posible que ello se deba al contexto escolar (de primeras letras) en el que se produce la digresion. Pero no hay que olvidar que la novela se ubica en ese mismo contexto y que los lectores ficticios del relato son precisamente los hijos de Perico (los "parvulillos" famosos de "Uno de tantos").

De todos modos, la digresión de Perico sobrepasa ese contexto inmediato para generalizarse a toda literatura. Así lo muestran los ejemplos propuestos en el mismo pasaje como ideal de lectura, tras una prueba de oir leer con los ojos cerrados. Antes de citar extensamente esa prueba, valdría la pena subrayar los rasgos que la definen: primeramente, la alusión repetida al oído como campo de acción de la lectura y como prueba de su eficacia; en segundo lugar, la mímesis de la lectura, la imitación de un estilo discursivo - de una performance de la lectura-como testimonio de su corrección y prueba de un saber auténtico; en tercer lugar, la mención de géneros discursivos (el sermón y la historia, la comedia y el discurso político, la poesía lírica dieciochesca y el catecismo) como formas oralizadas, susceptibles, por decirlo así, de una segunda lectura, extraña ya al ámbito natural de su origen; y en cuarto lugar, finalmente, el papel reservado a los ciegos como modelos de la lectura, papel implícito en la idea de un examen de oir leer con los ojos cerrados y que el maestro de Periquillo no cumple porque "no sabe leer":

Cuando oyereis a uno que lee un sermón como quien predica, una historia como quien refiere, una comedia como quien 
representa, etcétera, de suerte que si cerráis los ojos os parece que estáis oyendo a un orador en el púlpito, a un individuo en un estrado, a un cómico en un teatro, etcétera, decid: éste sí lee bien; mas si escucháis a uno que lee con sonsonete, o mascando las palabras, o atropellando los renglones, o con una misma modulación de voz, de manera que lo mismo lea las Noches de Young que el "Todo fiel cristiano" del catecismo, decid sin el menor escrúpulo: fulano no sabe leer; como lo digo ahora de mi primer maestro. Ya se ve, era de los que deletreaban c, a, ca; c, e, que; c, i, qui, etcétera; ¿qué se podía esperar? (8: 57-58).

\section{Entonación y estilo}

La propia novela de Lizardi ha sido escrita para oirse leer y resistir la prueba de una lectura escuchada con los ojos cerrados. Su autor aspira a una lectura politonal, bufonesca y sentenciosa a un tiempo, fundada en la variedad de tonos de la escritura, capaz de altemar - y articular en el pico de Perico- varios registros de estilo, como en contrapunto.

Algunas críticas del censor de Lizardi tienen su origen en esta circunstancia: así, la idea de que Lizardi novela en el "estilo de la canalla"; así, la molestia que confiesa el crítico por el descenso de registro estilístico perceptible en el curso de la novela; así, por último, la sugerencia de que el autor fracasa en su intento, de que la obra carece de variedad de estilos, de que su estilo es tan uniforme "como en su acción el chorrillo de alcantarilla" (8: 21).

Reitero estos temas para destacar el tipo de atención que el censor le ha prestado a la novela: atención al habla de la novela, al registro estilístico que cifra el habla, a las hablas o "estilos" de las escrituras. Lo mismo el autor que el censor opinan que cada personaje -o "interlocutor"- sintetiza un estilo que el autor imita y con el cual habla:

En mi novela se hallan de interlocutores colegiales, monjas, frailes, clérigos, curas, licenciados, escribanos, médicos, coroneles, comerciantes, subdelegados, marqueses, etcétera; yo he hablado 
en el estilo de esta clase de personas, ¿y así dice el señor Ranet que novelé "en el estilo de la canalla"? (8: 21)

Ahora bien, en la primera página de la novela, Perico declara su intención, no solamente de variar el estilo con fines de placer y entretenimiento (imitando, por ejemplo, el habla de muchos "interlocutores"), sino también de hacerlo a través del contrapunto de dos grandes géneros discursivos:

No creáis que la lectura de mi vida os será demasiado fastidiosa, pues como yo sé bien que la variedad deleita al entendimiento, procuraré evitar aquella monotonía o igualdad de estilo que regularmenie enfada a los lectores. Así es que algunas veces me advertiréis tan serio y sentencioso como un Catón; y otras tan trivial y bufonesco como un Bertoldo. Ya leeréis en mis discursos retazos de erudición y rasgos de elocuencia, y ya veréis seguido un estilo popular mezclado con los refranes y paparruchadas del vulgo (8: 43-44).

"Retazos", "rasgos", "refranes", "papamuchadas": tales son los elementos que componen la deshilada parla de Perico, mezcla inspirada en una tradición oral de fábulas y cuentos populares y en otra tradición más solemne, o más literaria, àsociada a la lectura del Catón y otros libros de fábulas y máximas morales recitadas y memorizadas por los párvulos en las escuelas de primeras letras del siglo XVIII. Todo en la parla de Perico es fábula, lectura infantil, apólogo, cuento sin sombra de verdad inventado para enseñar deleitando. 25

La falta de libros útiles para los escolares constituyó una suerte de lugar común en el siglo XVIII. El niño leía (o aprendía a recitar de memoria) la cartilla, el silabario, el Catón, pero la carencia de otros materiales reducía el campo de sus lecturas a la de los pronosticos, romances y patrañas condenadas por sus

25 "Fábula. Se entiende también por cuento u narración de cosa que ni es verdad ni tiene sombra de ella, inventado para deleitar, ya sea con enseñanza o sin ella: y las de la primer especie se llaman Apólogas y las de la segunda Milesias" (Diccionario de Autoridades s.v. "Fábula"). 
maestros. Así, el maestrescuela y cura de Chamacuero reprobaba, si no las Fábulas de Samaniego, sí los "cuentos de Pedro de Urdimalas, El Príncipe Lagarto y otras innumerables fruslerías" muy difundidas en su región y mejor conocidas de sus alumnos, razón por la cual decidió publicar sus propias Fábulas morales para la provechosa recreación de los niños que cursan las escuelas de primeras letras, como una forma de combatir "las referidas patranas" (Tanck 69). ${ }^{26}$

El Periquillo mismo se propone como una alternativa del $\mathrm{Ca}$ tón, o del libro de máximas y fábulas, o de los cuentos y "patrañas" populares tan conocidos de nuestros escolares del siglo XVIII. Aspira a ser tan fructífero "como un Catón", y a la vez tan trivial "como un Bertoldo", es decir: como ese astuto personaje folklorico que hasta hace poco tiempo formaba parte de la biblioteca popular americana. ${ }^{27}$

Fábula, testamento, sermón, cuento, novela: ninguno de estos géneros literarios - vendidos en puestos y alacenas - agotaría la forma del Periquillo. Más que elegir un "género" se elige un registro de estilo, registro que suele ser común a la redacción de un fragmento periodístico y a la escritura de la novela. No es casual, por ejemplo, que al anunciar su Alacena de Frioleras, en mayo de 1815 , Lizardi hable de ella como de un periodico "rascuachi110 " o "trapientuzco" (Obras 4: 23), ni que en agosto del mismo

${ }^{26}$ El propio Lizardi publicó, en 1817 , su libro de Fábulas, contemporáneo casi de las Fábulas políticas y militares del árcade José María Lacunza, obstinado detractor de Lizardi.

${ }^{27}$ Bertoldo es el protagonista de un popular relato italiano cuya primera versión española data de 1745: Historia de la vida, hechos y astucias sutilisimas del rústico Bertoldo, la de Bertoldino su hijo y la de Cacaseno su nieto. De acuerdo con un testimonio chileno de 1907, aún era posible encontrar "en todos los hogares pobres y donde quiera que haya niños" lo mismo la Historia de Carlomagno que Las Mil y Una Noches y "las astucias de Bertoldo" (Vicuña Cifuentes 532). El propio maestro de Perico opinaba "que nunca convenía que yo leyera Soledades de la vida, las Novelas de Zayas, Guerras civiles de Granada, La historia de Carlo Magno y doce pares, ni otras boberas de éstas, que lejos de formar, cooperan a corromper el espíritu de los niños, o disponiendo su corazón a la lubricidad, o llenando su cabeza de fábulas, valentías y patrañas ridículas" (8: 72-73). 
año describa su propio trabajo en términos que recuerdan los del Periquillo:

Su estilo es un estilo de bodegón. [...]. Sólo nos emboca moralidades añejas, sátiras frías, y cuentos de cocina, y esto con una cantinela monótona y nevada. Lo único que tiene es lo que más enfada, y es aquel estilo faceto, truhán y chocarrero con que sin tener sal quiere las más veces arrancar la risa a sus miserables lectores (Obras 4: 118).

Lo mismo sucede, en diciembre de 1823, con El Payaso de los Periódicos, ajeno a toda "severidad catoniana", vestido de "remiendos" y "retacitos" — como un payaso pobre - y cuyo "papel en la escena de los periódicos" es hacer reír, servir de "payaso, arlequín o faceto" a los tristes lectores:

Queremos que los pobrecitos de la última plebe nos entiendan; que se enamoren de nueśtro estilo llano y popular; que no se cansen de nuestra severidad y pedantismo, y que atraídos de la chocarrería, de la sátira, del refrancillo vulgar y la frase de pulquería, se empeñen en leer el Payaso, [...] sin tono de lección (Obras 5: 20).

Lo que se juega, pues, en la parla de Perico no es una mera cuestión de géneros o autoridades, sino una cuestión de estilo: de entonación y estilo. Compárese la expresión de la primera página del libro - "aquella monotonía o igualdad de estilo que regularmente enfada a los lectores" (8: 43) — con la otra frase utilizada por Perico en su lección de lectura, y que describe uno de los "modos más comunes de leer": "con cierta monotonía o igualdad de tono que fastidia" (8: 57).

La lección de Perico se aplica entonces a la lectura de la novela - y al estilo de la escritura de la novela. Variar el estilo de la novela es variar el tono de su lectura. Leer la novela correctamente implica saber distinguir sus estilos y saber entonar un texto escrito para leerse en voz alta.

Monotonía de estilo en la escritura; monotonía de tono en la lectura: fenómenos que enfadan o fastidian al lector y al oyente; 
al iletrado, al huérfano y al plebeyo. Politonía de la parla de Perico - perico de Perico-, articulada en el juego satírico como una figura de la voz, como una parodia que mimetiza y disfraza los más dispares gestos discursivos, como un arte de la lectura que acopla ciertos registros de estilo con otras tantas formas de modulación de la voz.

\section{Memoria y lectura}

En las "Notas de El Pensador", añadidas por él al fin de la novela, Lizardi explica que Perico "escribio su vida en un estilo ni rastrero ni finchado", empleando "un estilo casero y familiar", accesible a todos, que "no omite muchas veces valerse de los dicharachos y refranes del vulgo" y que usa "de la chanza" para no hacer su obra "fastidiosa" (9:414). Idéntico juego de estilos al presentado en la obertura del libro; idéntica técnica de entonación -pero aplicada, en la última página de la novela, ya no sólo al modo de lectura de la Vida, sino también al gusto y al fruto de la lectura:

Un libro de éstos lo manosea con gusto el niño travieso, el joven disipado, la señorita modesta y aun el pícaro y tuno descarado. Cuando estos individuos lo leen, lo menos que piensan es en sacar fruto de su lectura. Lo abren por curiosidad y lo leen con gusto, creyendo que sólo van a divertirse con los dichos y cuentecillos, pero cuando menos piensan, ya han bebido una porción de máximas morales que jamás hubieran leído escritas en un estilo serio y sentencioso ( $9: 414)$.

Leer con gusto y leer con fruto son dos modos de leer, dos descripciones de la lectura que Perico emplea en varios momentos de la novela. Pero ¿qué significan esas palabras?, ¿cuáles son las maneras de leer a las que alude el juego de esas dos expresiones? A primera vista, se trata de un juego de elementos complementarios: el gusto y el fruto serían dos aspectos de una lectura total, pluriestillistica y politonal, capaz de añadir al "pasatiempo" 
de leer un aprovechamiento moral de la lectura. De nada serviría gozar sus "extravíos", divertirse con sus "largas digresiones y lances burlescos", si el lector no supiera desgranar la paja de la lectura. ${ }^{28}$

Otro pasaje de la novela ayudaría a precisar el sentido de la lectura con fruto de la novela. Me refiero al capítulo en el que Pedro cuenta la educación de su amo - el chino de la isla de Saucheofú - a manos de cierto capellán que funge, enseñandolo a leer y escribir, como su maestrescuela:

Luego que venían de algún paseo, se encerraban a platicar mi amo y el capellán, quien en muy poco tiempo lo enseñó a hablar y escribir el castellano perfectamente, y lo emprendió mi amo con tanto gusto y afición que todos los días escribía mucho, aunque yo no sabía qué, y leía todos los libros que el capellán le daba, con mucho fruto porque tenía una feliz memoria (9: 294).

Leer con fruto significa, entonces, recordar lo leído, inscribir la lectura en la memoria, conservar la lección. ${ }^{29}$ Y lo mismo se aplica a la lectura fructífera del Periquillo. Como se apunta al final de la novela, el lector vuelve en sí del "Extasis delicioso de la diversión" para reflexionar con seriedad la crítica, para aplicarla a sí mismo, pero también -y esto ya en el ámbito de una mnemotecnia de la lectura- para retenerla, para "tener presente la lección" (9: 414).

Lo que me interesa destacar aquí es el aspecto técnico, y no moral, que une memoria y lectura en el Periquillo. Las disposiciones testamentarias del primer capítulo contenían ya una sugerencia de memorización: "Aprended las máximas que os enseño,

28 "Yo sólo os ruego lo que otras veces, esto es, que no leáis mi vida por un mero pasatiempo; sino que de entre mis extravíos, acaecimientos ridículos, largas digresiones y lances burlescos, procuréis aprovechar las máximas de sólida moral que van sembradas [...]. Esto será saber entresacar el grano de la paja, y de este modo leeréis no sólo con gusto sino también con fruto el presente capítulo y los que siguen" (9: 141).

${ }^{29} \mathrm{El}$ chino lee los libros del capellán, libros devotos, edificantes, fructíferos. Pero el "fruto" de la lectura depende, en última instancia, de la "feliz memoria" del discípulo. 
[...] comenzad a leer" (8: 45). Ciertos pasajes de la novela han sido escritos para leerse y para releerse, para recitarse y memorizarse, teniendo en cuenta la función mnemotécnica tradicionalmente depositada en el verso: "Antes de cerrar esta digresión, os quiero yo dar unos cuantos consejos acerca de la misma materia, y han de ser en verso porque los retengáis más fácilmente en la memoria" (8: 203).

Leer, memorizar, recitar: tres operaciones que huellan el surco de la voz - murmullo y eco de la lectura. El lector balbucea unos versos para sus adentros, intentando grabarlos en su memoria, repitiéndolos y recitándolos confusamente, en un afán por vocalizarlos fuera de los límites de la novela. Pero veamos un último ejemplo. La muerte del padre - y su legado— dan lugar a otra grave escena de memorización:

Me dio una carta cerrada de mi padre y con ella la noticia de su fallecimiento. [...]. Dos días pasaron sin que yo me atreviese a abrir[la] [...]. Al cabo de tres días abrí la carta, cuyo contenido lo lé tantas veces que se me quedó en la memoria y por ser sus documentos digna herencia de vuestro abuelo [se trata de una serie de máximas morales], os la quiero dejar aquí escrita (8: 205206).

Perico copia de memoria una carta para sus hijos. Y esa carta le ha sido legada - en un trance identico al que ahora le toca padecer a él- por su propio padre. Pero la carta ha permanecido cerrada. Perico no se ha atrevido a abrirla y no ha leído más que el sobrescrito. Al cabo de tres días, ha abierto por fin la carta y la ha releído tantas veces que ha terminado por memorizarla. Es por eso que ahora, en su lecho de muerte, Perico musita esas máximas al transcribirlas para sus hijos. Ahora son ellos quienes habrán de memorizarlas.

Todos esos elementos apoyan la lectura fructífera de la carta paterna: la muerte del padre; la "carta cerrada" y el "sobrescrito"; 30 la repetición y la recitación; el legado y la lectura doméstica.

${ }^{30} \mathrm{El}$ "sobrescrito" tiene valor de recordatorio: "Dos días pasaron sin que yo me atreviese a leer la carta, pues cada vez que la quería abrir, leía el 
Todos ellos giran en torno al padre y en torno a la memoria - a su memoria- como fruto del texto.

Ya hemos visto que el juego estilístico de la novela se acopla con una técnica de entonación - una modulación de la lectura en voz alta. Ahora bien, la "utilidad" de la novela consiste en desprender de ese doble juego una memoria de la lectura, con sus propias formas de recordacion, distintas a la simple memorización de máximas versificadas. No basta con repetir las máximas "como perico". Hay que darle un cuerpo a ese "perico", hay que construirle una imagen a la voz:

Los libros morales serios es cierto que enseñan, pero s6lo por los oídos, y por eso se olvidan sus lecciones fácilmente. Éstos instruyen por los oídos y por los ojus. Pintan al hombre como él es, y pintan los estragos del vicio y los premios de la virtud en acaecimientos que todos los días suceden. Cuando leemos estos hechos nos parece que los estamos mirando, los retenemos en la memoria, los contamos a los amigos, citamos a los sujetos cuando se ofrece; nos acordamos de éste o del otro individuo de la historia luego que vemos a otro que se le parece, y de consiguiente nos podemos aprovechar de la instrucción (9:415).

Perico es una figura de la voz, pero también una imagen de la memoria. Por eso, la estampa del principio anuncia:

No es éste el Periquillo que cantando o haciendo no sé qué se llevó el viento.

A este perico no se lo lleva el viento. Tiene un valor ejemplar y un valor mnemotécnico. Sus lecciones entran "por los oídos" -a través de la voz- y "por los ojos" - por el ejemplo-: son inolvidables. Perico escrito para escucharse y mirarse, para acordarse, para recordar y para recordarse, para citarse y contarse en

sobrescrito que decía: «A mi querido hijo Pedro Sarmiento; Dios lo guarde en su santa gracia muchos años». Y entonces se estremecía mi corazón sobremanera, y no hacía más que besarla y humedecerla con mis lágrimas, pues aquellos pocos caracteres me acordaban el amor que siempre me había tenido, y su constante virtud, que me había inspirado" (8: 205-206). 
una nueva tradición oral. Como la figura de Pedro Sarmiento grabada en la estampa que anuncia el libro, el Periquillo es un teatro de la memoria: espacio imaginario que cifra - en el silencio de la imagen- la voz.

\section{Lizardi o el perico}

Siete años después de publicar el Periquillo, Lizardi ideaba un periódico satírico con otro perico como protagonista: El Hermano del Perico que cantaba la Victoria (Obras 5: 25-73). Sus primeras frases relataban un diálogo "en el portal", con el autor y una mujer como interlocutores: la mujer le ofrece a Lizardi un loro _."un hermoso perico que llevaba"_-; él se resiste diciendo que el animal "solo hablaba despropósitos y era buen término de comparación de un tonto"; ella, por fin, insiste en vendérselo, solicitando "cuatro pesos lo último":

- No, señor, este perico no habla desatinos, sino cosas muy buenas. Sabe mil lindezas, canta muy buenas coplas, aprende cuanto oye y, sobre todo, es muy barato (Obras 5: 27).

Si la mujer de la plaza no miente, este nuevo perico de Lizardi "habla", "canta" y "aprende cuanto oye" - sin contar con que es tan barato como el Periquillo. Una vez en su casa y solo en su gabinete, Lizardi oye entonar al "lorito" - que "no había hablado sino palabras vagas y corrientes" - una de esas coplillas que sirven de ayuda-memoria, tras de lo cual, para susto y sorpresa de Lizardi, que no cree en los cuentos de las viejas, se entabla un diálogo entre loro y autor:

Al oír yo esto, no pude menos que llenarme de un profundo pavor, y quise huir, creyendo que aquél no era perico, sino duende, diablo, endriago, vampiro, brucolaco u otro bicho de estos [...]; [y] acobardado con lo que acababa de oír, creí cuantas fábulas me habían contado, siendo ninoo, las viejas de mi casa y las ajenas (28-29). 
Pero la "magia encantadora" de esta fábula o cuento del perico no se reduce a la habilidad de éste para entablar una conversación. El "lorito" tiene un alma humana - y aunque no un cuerpo humano, sí ha heredado de esa estirpe la voz. Vale la pena citar in extenso la estirpe del "lorito" de Lizardi:

- Has de saber que no soy tan perico como piensas. Mi cuerpo es de tal porque, en efecto, mis padres fueron un loro y una cotorra de la Huasteca. [...]. Nunca los conocí [...]. Me tocó en suerte el alma de un filosofo viejo y experimentado, que así ha variado cuerpos en el mundo como varían los cómicos trajes y representaciones. El espíritu de este filosofo que me anima ha animado cuerpos de reyes, de ministros, de magistrados, de jueces, de generales, de damas y de clérigos, de frailes, de ladrones, de usureros, escribanos, médicos, boticarios y toda clase de personas; hasta que por haberse portado mal en el cuerpo de un escritor que lo hizo charlatán, fue sentenciada por Plutón a servir a un perico cual yo soy (29).

"Un perico pitagórico o un Pitágoras apericado" (44): tal es la disyuntiva que agobia al lorito de Lizardi. Y es que el alma que anima su cuerpo es la de Pitágoras, el puro, que prescribía el silencio como cura del alma. Su cuerpo es, pues, un castigo; su voz, escarmiento del alma. En ese loro reencarna la parla de Perico, la charlatanería del escritor, cuya alma de perico clamaba por animar un cuerpo de perico.

El loro de Lizardi no desmiente su estirpe lucianesca. En su opúsculo El sueño o el gallo, Luciano ponía a dialogar a un gallo "charlatán y chillón" con Micilo, el zapatero. Al igual que el lorito de Lizardi, el "gallo filosofo" es una de tantas reencamaciones de Pitágoras - quien fue Aspasia, la cortesana, y Crates, el cínico; rey, pobre, sátrapa y luego caballo, cuervo y rana. $Y$ aunque no fue, al parecer, perico, también el perico, como el gallo, es "un ave humilde en apariencia que lleva en sí [muchas] almas" (Luciano 382).

MICILO: ¡Zeus milagroso y Heracles conjurador de desgracias! ¿Qué maleficio es éste? ¡El gallo ha hablado con voz humana! (Luciano 365) 
Pero ¿qué es lo que repite un loro sino "mil majaderías lorunas" (37)?, ¿qué repite un perico sino "pericadas" (67)? Las majaderías del "lorito" de Lizardi son versos y refranes groseros que pudo inventar "Perico el de los palotes" (56):

"¿Quién pasa?, ¿quién pasa?, ¿hay pan para el loro?, azotitos y todo" (37); “ ¡Ah!, ¡ah!, ¡ah!, ¡ah! ¿No hay pan para el loro? ¿Quién pasa?, ¿quién pasa? El santísimo sacramento que va a su casa. ¿Tu mujer es hermosa? Como una rosa, puerca y golosa. Tan, tan. ¿Quién es? El fraile. ¿Qué quiere el fraile? Zapatitos azules, puntas al aire. ¡Cuerno en el fraile!” (60).

Hay hombres que "hablan como pericos" (37), o "como el perico" (44), y pericos que hablan con voz humana. La voz de Perico carecía de ese tono meloso, chillón y majadero que le añade la voz del periquito. Y es en el tono - recuérdese la lección de Periquillo - donde se juegan el "saber leer" y la lectura de la novela. Por eso ese lorito que "aprende cuanto oye" y que aprecia una lectura en voz alta puede decirle al autor del Periquillo: "he oído leer tus papeles" (37). ${ }^{31}$

\section{La Sociedad Pública de Lectura}

Lectura en voz alta del Periquillo, lectura silenciosa... El 22 de julio de 1820, Lizardi daba a la imprenta un papel que arroja otra luz sobre la materia. Se trata de un "proyecto realizado" cuyas primeras líneas rezan del siguiente modo:

En la calle de Cadena se abrirá mañana una accesoria, letra $\mathrm{A}$, en la que se hallarán los más de los papeles que han salido a luz y los que sucesivamente vayan saliendo.

${ }^{31}$ A la lección de lectura de Periquillo corresponde la breve lección de canto de nuestro "lorito": "Una monja, en un teatro, si quiere cantar un sainete, chillará; y si una cómica quiere cantar maitines y laudes en un coro de monjas, aullará. Las dos cantarán; pero las dos mal, porque ninguna canta en su tono" (39). 
A esta sala o accesoria se ha nombrado sOcIEDAD PÚBLICA DE LECTURA (Obras 10: 225).

Los reglamentos de esta "sala o accesoria" ilustran, de manera elocuente, ciertos hábitos de lectura desprendidos de la lectura de la novela y reiterados en una nueva época _-la de la libertad de imprenta. La intención del proyecto es muy clara: fomentar la "lectura pública", aunque ello signifique un sacrificio (por disminución de las ventas) de "autores y vendedores". "Yo [dice Lizardi] soy escritor y tengo alacena de papeles, y por lo mismo, si se verifican las pocas ventas lo debo resentir primero y con doble motivo" (226).

El argumento de Lizardi es pragmático y mercantilista. Él mismo es autor y vendedor de "papeles": la lectura se le presenta como negocio, como mercancía. Entre el "saber leer" y el "leer" introduce un tercer elemento: el "poder leer", o comprar, los "papeles" para la lectura. Por eso, la ausencia de lectura (y lo mismo podría decirse del hábito de leer en voz alta) no es para él sólo un fruto del analfabetismo:

De nada sirve la libertad de imprenta a quien no lee, y muchos no leen no porque no saben o no quieren, sino porque no tienen proporción de comprar cuanto papel sale en el día (225).

Aparte de los lectores ocasionales, la sociedad tendrá dos tipos de "suscriptores de lectura": lectores mensuales, "y por todo el día", y lectores callejeros - aquellos que se quieran "suscribir para la calle" y recibir los "papeles" de manos de los repartidores. Esta última forma de suscripción recuerda la lectura circulante de los pliegos, al igual que el énfasis en la conservación material de los "papeles":

Si alguno se quisiere suscribir para la calle, se le llevarán por el mismo precio a su casa todos los papeles que hayan salido el día anterior [...]. Si algún papel se extraviare, rompiere o ensuciare, deberá pagarlo el suscriptor (226). 
que traduce a las reglas de la "lectura pública" las escenas de copia de Periquillo: "3a. La persona que quisiere copiar de algún papel lo que le parezca, podrá hacerlo, pues para eso habrá recado de escribir y papel que se venderá ahí mismo" (226). El costo de la entrada a la accesoria sería de un real, y de tres pesos mensuales para los suscriptores.

Ahora bien, la descripción del cobro a la entrada de la accesoria da lugar a una curiosa digresión lizardiana acerca de los hábitos tradicionales de lectura y, en particular, de la lectura en voz alta. Lizardi adivina el comportamiento de los lectores en la primera regla de su Sociedad de Lectura:

El real se pagará en la entrada, y lo pagará todo entrante aunque diga que no va a leer, sino que va acompañando al que pagó. Esta advertencia es precisa, pues cualquiera pretextaría que iba con un amigo y se entraría a oír de balde, lo que no podía resultar de ningún provecho a la casa (226).

Tras la figura del no-lector, se oculta, pues, un oidor "de balde", un oyente de la lectura en voz alta. Ahora bien, la Alacena de Frioleras relataba, en 1815, la escena de otra lectura "de balde", en un puesto del Portal de Mercaderes. Y ahí es posible hallar premoniciones, lo mismo del lorito de la mujer del portal que de la Sociedad Pública de Lectura:

En estas pláticas nos fuimos yendo hacia el Portal de los Mercaderes, y cuando menos pensé, ya estábamos en el puesto de la gaceta. [...]. Lo célebre era que los que pagaban efectá [sic] los papeles públicos, ni los leían allí, ni se quedaban por todo aquello; pero los coqueros que iban a leer de balde, que eran hartitos, [...] los criticaban y mordían a su gusto (Obras 9: 117).

Entre oir y leer de balde, no existe más diferencia que la que hay entre el loro y la pluma de Lizardi. Por eso, uno de tantos charlatanes que muerden papeles a su gusto retrata así al autor del Periquillo: "Es un tonto de marca, escritor famelico, y hablador por naturaleza" (Obras 9: 118).

La Sociedad Pública de Lectura es, en cierta manera, la imagen utópica —corporizada, reglamentada, mercantilizada- del 
Antiguo Régimen cultural novohispano. Es una biblioteca popular, en cuanto intento, marginal, por darle forma a una lectura en voz alta, al nomadismo de los pliegos sueltos, a la lectura efímera de los papeles impresos, a la circulación de copias manuscritas. Ni el diluvio de folletos impresos en los albores de la Independencia, ni la obsesion liberal por abatir los índices de analfabetismo agotarían el significado de la sociedad proyectada por Lizardi - una biblioteca de la lectura en voz alta, compuesta de papeles circulantes, fruto efímero, como esos papeles, de la cultura del Periquillo. ${ }^{32}$

\section{BIBLIOGRAFÍA CITADA}

Alzate y Ramfrez, José Antonio de. Obras I. Periódicos. Ed. Roberto Moreno de los Arcos. México: UNAM, 1980.

AMADES, JOAN. "El testamento de animales en la tradición catalana." Revista de Dialectología y Tradiciones Populares 18 (1962): 339394.

CABrera y QunNtero, Cayetano. Escudo de armas de México. [Imprenta de la Viuda de don Joseph Bernardo de Hogal, 1746.] Ed. facs. Méxịco: IMSS, 1981.

Catulo, Cayo Valerio. Cármenes. Trad. Rubén Bonifaz Nuño. México: UNAM, 1969.

Cervantes Saavedra, Miguel de. Don Quijote de la Mancha. Ed. Francisco Rodríguez Marín. 9ª ed. Madrid: Espasa Calpe, 1969. Vol. 8. Cros, Edmond. "Structure testamentaire et discours reformiste dans $E l$

${ }^{32}$ El proyecto de la Sociedad Pública de Lectura fracaso a los pocos días de haberse iniciado. Sobre el tránsito de la lectura en voz alta a la lectura silenciosa, dice Zumthor que "lo que, a largo plazo, impuso poco a poco la lectura silenciosa y puramente ocular fue la multiplicación del número de los escritos en circulación" (126). Y añade: "Al principio, sólo ciertos ambientes se vieron afectados [...]. Las universidades, en el siglo XIV, que abrieron bibliotecas para los estudiantes, emitieron reglamentos que exigían la lectura silenciosa; en el siglo XV se convirtió en norma de obligación absoluta". Para Zumthor, "los resultados de un cambio tal [es decir, del paulatino desuso de la lectura en voz alta y la generalización de la lectura silenciosa] son a largo plazo más determinantes, en la formación del espíritu «moderno», que la invención de la imprenta - la cual no hace sino ratificarlos y volverlos irreversibles" (126). 
Periquillo Sarniento." De l'engendrement des formes. Montpellier:

Université Paul Valery, 1990. 149-176.

Diccionario de Autoridades. Ed. facs. 3 vols. Madrid: Gredos, 1984.

Egutara y Eguren, Juan Josê de. Prólogos a la Biblioteca Mexicana.

Trad. Agustín Millares Carlo. $2^{a}$ ed. México: FCE, 1984.

Fernández de Lizardi, José Joaqutn. Obras 8-9. Novelas. El Periquillo

Sarniento. Noches tristes y día alegre. Ed. Felipe Reyes Palacios.

México: UNAM, 1982.

- - Obras 3. Periódicos. Ed. María Rosa Palazón y Jacobo Chencinsky. México: UNAM, 1968.

- - Obras 4. Periódicos. Ed. María Rosa Palazón. México: UNAM, 1970.

- - Obras 5. Periódicos. Ed. María Rosa Palazón. México: UNAM, 1973.

- - Obras 10. Folletos (1811-1820). Ed. María Rosa Palazón e Irma Isabel Fernández Arias. México: UNAM, 1982.

FRENK, MARGrT. " "Lectores y oidores». La difusión oral de la literatura en el Siglo de Oro." Actas del Séptimo Congreso de la Asociación Internacional de Hispanistas. 2 vols. Roma: 1982. 1: 101-123.

- —. "La ortografía elocuente. Testimonios de lectura oral en el Siglo de Oro." Actas del VIII Congreso de la Asociación Internacional de Hispanistas. Madrid: Istmo, 1986. 549-556.

- _. "Ver, oír, leer..." Homenaje a Ana María Barrenechea. Madrid: Castalia, 1984. 141-156.

González Casanova, Pablo. La literatura perseguida en la crisis de la Colonia. [El Colegio de México, 1958]. México: SEP, 1986.

Guía de Forasteros I. México: INBA, 1984.

Hafter, Monroe Z. "Ambigüedad de la palabra "público» en el siglo XVIII.” NRFH 24 (1975): 46-63.

Luciano. El sueño o el gallo. Obras 1. Trad. Andrés Espinosa Alarcón. Madrid: Gredos, 1981. 362-392.

Maneiro, Juan Luis. Vidas de algunos mexicanos ilustres. Trad. Alberto Valenzuela Rodarte. México: UNAM, 1988.

Matos Moctezuma, Eduardo. El negrito poeta mexicano y el dominicano. México: Porrúa, 1980.

Miranda, José y Pablo Gonzalez Casanova. Sátira anónima del siglo XVIII. México: FCE, 1953.

Reyes, Alfonso. "El Periquillo Sarniento y la crítica mexicana." Obras completas IV. México: FCE, 1956. 169-178.

Santamarta, Francisco J. Diccionario de mejicanismos. México: Porrúa, 1954. 
Spell, Jefrerson Rea. Bridging the Gap. Articles on Mexican Literature. México: Libros de México, 1971.

TANCK DE EsTRADA, DoRothy. "La enseñanza de la lectura y de la escritura en la Nueva España, 1700-1821." Historia de la lectura en México. México: Ediciones del Ermitaño / El Colegio de México, 1988. 49-93.

TrabUlse, Elías. Los manuscritos perdidos de Sigüenza y Góngora. México: El Colegio de México, 1988.

Vicuña Cifuentes, Julio. Romances populares y vulgares recogidos de la tradición oral chilena. Santiago de Chile: Imprenta Barcelona, 1912.

Zavala, IrIs M. Clandestinidad y libertinaje erudito en los albores del siglo XVIII. Barcelona: Ariel, 1978.

Zumrhor, Paur. La letra y la voz. De la "literatura" medieval. Trad. Julián Presa. Madrid: Cátedra, 1989. 